\title{
Study on Hydrolysis Reaction Rate of Several Chemical Warfare Agents
}

\author{
Dai Xuezhi ${ }^{1, a}$ \\ ${ }^{1}$ Institute of NBC Defense, Chinese PLA Army, Beijing, China
}

\begin{abstract}
According to the first-order kinetic reaction equation, the hydrolysis rate constants of homogeneous and heterogeneous phase of eight poisons under different conditions were calculated, and the relationship between hydrolysis rate constants and temperature was obtained according to the arrhenius formula, and the activation energy of hydrolysis reaction of some poisons was calculated. The evolution curve of homogeneous hydrolysis rate of $0.5 \mathrm{~g} / \mathrm{L} \mathrm{HD}$ with time was collected by T-135 method, and the hydrolysis rate was $0.1 \mathrm{~min}^{-1}$ and the half-life was $7 \mathrm{~min}$. Poison concentration, $\mathrm{pH}$ of system, environmental temperature and structural composition of soil all affect the hydrolysis rate of Chemical Warfare Agents.
\end{abstract}

\section{Introduction}

Many disinfectants are formulated with water as one of their components. In these water-based systems, chemical warfare agents such as Tabun (GA), Sarin (GB), Soman (GD), VX, mustard gas (HD), Lewisite (L), phosgene (CG) and Bitz (BZ) will undergo hydrolysis reaction ${ }^{[1]}$. In the research and development of decontamination agents, though many scholars hope to find a faster, more efficient and mild disinfection method, instead of simply relying on hydrolysis to complete the decontamination of military chemical agents, it is very meaningful to understand the contribution of hydrolysis to decontamination compared with other decontamination agents with stronger activity. Therefore, this paper summarized some literatures about poison hydrolysis.

Chemical reaction kinetics, as an important component of chemical theory, can answer the question of the rate and mechanism of chemical reaction. Up to now, the firstorder or second-order reaction kinetic model is often used in the literature to deal with the reaction process kinetic curve and find out the first-order or second-order reaction kinetic rate constant; The apparent activation energy can be calculated based on the rate constant at different temperatures and Arrhenius equation ${ }^{[2]}$.

\section{Materials and Methods}

\subsection{Materials}

752 spectrophotometer, Shanghai Precision Scientific Instrument Co., Ltd.; Model 501A super thermostat, Shanghai Laboratory Instrument Works Co., Ld., micropipette, Eppendorf Co., Ltd., Germany; $25 \mathrm{~mL}$ test tube, Beijing glass instrument factory; HD ( $\geq 95 \%)$; Anhydrous ethanol (analytically pure), Dasen Chemical
Products Sales Co., Ltd.; Thymol phthalide (analytically pure); Potassium hydroxide (analytically pure).

\subsection{Methods}

Take a $25 \mathrm{~mL}(\varphi=27 \mathrm{~mm})$ test tube with stopper, inject about $5 \mathrm{ml}$ of deionized water, put it in a thermostat at $25^{\circ} \mathrm{C}$, add a certain amount of HD ethanol solution with micropipette, the concentration of HD in the reaction system is $0.5 \mathrm{~g} / \mathrm{L}$, ethanol is $4 \%$, let it stand for a certain time, then immediately measure the residual concentration of HD in the system by T135 method, collect the residual concentration of HD at different times, and then calculate its hydrolysis.

\section{Results and Discussion}

\subsection{Homogeneous hydrolysis of HD}

The solubility of HD in water is low, only $0.8 \mathrm{~g} / \mathrm{L}$ at $20^{\circ} \mathrm{C}$. HD dissolved in water will hydrolyze quickly, and the main factor affecting the hydrolysis rate of HD is the dissolution and diffusion of HD. The final products of HD hydrolysis are thiodiglycol and two molecules of hydrogen chloride ${ }^{[3]}$. The reaction equation is:<smiles>OCCS(CCO)(CCO)CCCl</smiles>

The hydrolysis of HD first produces half mustard gas, and then the half mustard gas continues to hydrolyze to produce thiodiglycol. In the process of generating semimustard gas, sulfonium ions are first generated, and the reaction between sulfonium ions and water molecules to generate semimustard gas is much faster than the

\footnotetext{
a Corresponding author: 297896810@qq.com
} 
generation of sulfonium ions. However, semi-mustard gas is unstable and easily reacts with water molecules to form thiodiglycol. The decisive step of HD hydrolysis reaction is to generate sulfonium ions, which can be considered as bilateral hydrolysis, that is, complete hydrolysis to generate thiodiglycol ${ }^{[4]}$.

Considering HD hydrolysis as a first-order reaction, there are:

$$
-\frac{d C_{A}}{d t}=k t \Rightarrow \ln C_{A}=-k t+d
$$

According to the linear relationship between $\ln C_{A}$ and $\mathrm{t}$, the average rate constant $\mathrm{k}$ of HD hydrolysis reaction can be calculated. Homogeneous hydrolysis is dissolved HD. In order to ensure homogeneous hydrolysis of HD, HD can be dissolved in absolute ethanol first and then in water. At $25^{\circ} \mathrm{C}$, the hydrolysis rate of $0.5 \mathrm{~g} / \mathrm{L} \mathrm{HD}$ increases exponentially with time, and the hydrolysis rate is fast at first and then slow. As shown in Figure 1, the hydrolysis rate of $\mathrm{HD}$ can be calculated as $0.1 \mathrm{~min}^{-1}$ and the half-life is $7 \mathrm{~min}$ by the above formula.

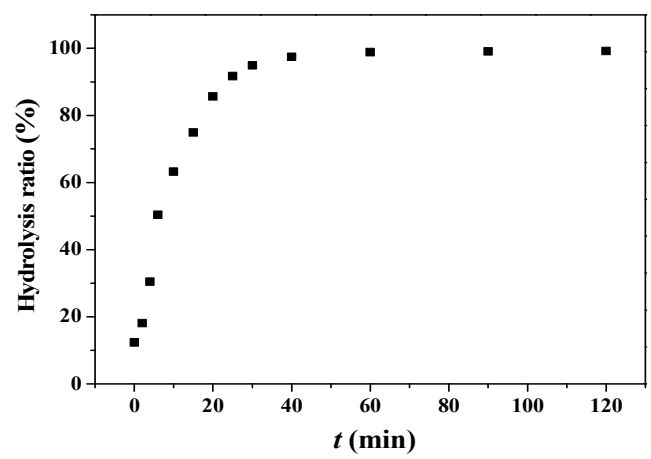

Figure 1. The change of hydrolysis rate of $0.5 \mathrm{~g} / \mathrm{L} \mathrm{HD}$ at $25^{\circ} \mathrm{C}$ with time

\subsection{Homogeneous hydrolysis of various poisons}

According to the first-order kinetic reaction equation, the hydrolysis rate constants of homogeneous and heterogeneous poisons were calculated by using the experimental data of hydrolysis rates of various poisons given in the literature, and the relationship between hydrolysis rate constants and temperature was obtained according to arrhenius formula, and the activation energy of hydrolysis reaction was calculated. The rate constants and activation energies of homogeneous and heterogeneous hydrolysis of various poisons are listed in Table 1 and 2 .

It can be seen from Table 1 that Tabun (GA) is attacked by parallel hydroxyl nucleophiles in the $\mathrm{pH}$ range of 3 9 to form pentacoordination intermediates, which are hydrolyzed to form cyanide ions and dimethyl amino phosphonic acid monoethyl ester. J.Epstein gave the hydrolysis rate constants of GA in seawater at different temperatures, and the activation energy was $71.1 \mathrm{~kJ} / \mathrm{mol}$, which was basically consistent with the hydrolysis rate constants given by Lennart Larsson, indicating that the effects of ionic strength and seawater on hydrolysis rate were limited. M.M.Demek determined that the hydrolysis rate constant of Sarin GB in seawater is $2.63 \mathrm{~h}^{-1}$, which is nearly 40 times faster than that in pure water under the same experimental conditions. $\mathrm{Ca}^{2+}$ and $\mathrm{Mg}^{2+}$ from seawater can significantly catalyze the hydrolysis of GB. It was also found that the hydrolysis rate constant decreased with the increase of $\mathrm{pH}$ in the range of $1 \sim 4$, but remained unchanged in the range of $4 \sim 6.5$. When $\mathrm{pH}$ was above 6.5 , the hydrolysis rate increased with the increase of $\mathrm{pH}$. The hydrolysis product of GD is mainly pinanyl methylphosphonate, and both acidic and alkaline environments can accelerate the hydrolysis reaction of GD. In addition, it is found that GD can be completely hydrolyzed in 5 minutes in $5 \% \mathrm{NaOH}$ aqueous solution and 45 minutes in $0.1 \mathrm{HCl}$ aqueous solution at $20^{\circ} \mathrm{C}$. VX mainly breaks P-S under acidic and alkaline conditions, and the hydrolysis product is $\beta$-diisopropylaminoethyl mercaptan. However, when P-O breaks under weak alkaline conditions, VX degreasing and hydrolysis reaction takes place to produce $\mathrm{S}-\beta$ diisopropylaminoethyl thiomethylphosphonic acid. When VX concentration is in the range of $2 \sim 5.5 \mathrm{~g} / \mathrm{L}$, the hydrolysis rate constant is basically unchanged. Hydrolysis of CG is a part of nucleophilic substitution reaction or acylation reaction. Affinity substitution reaction occurs at acyl chloride site $(-\mathrm{COCl})$, and the hydrolysis rate of dissolved CG is relatively fast. Adding alkali will accelerate the hydrolysis of CG. BZ is not easy to hydrolyze at room temperature, and heating or adding alkali can accelerate its hydrolysis reaction. The hydrolysis products are diphenylglycolic acid and quininol, but hydrolysis is slow under acidic conditions. Controlling $\mathrm{pH}$ value can accelerate the hydrolysis reaction rate.

Table 1. Homogeneous hydrolysis rate constant and activation energy of various poisons

\begin{tabular}{c|c|c|c|c|c|c}
\hline \multirow{2}{*}{ Type } & \multicolumn{3}{|c|}{ Experiment Condition } & $\begin{array}{c}\text { Speed } \\
\text { Constant }\end{array}$ & $\begin{array}{c}\text { Activation Energy } \\
(\mathrm{kJ} / \mathrm{mol})\end{array}$ & \multirow{2}{*}{ Remarks } \\
\cline { 2 - 6 } & $T\left({ }^{\circ} \mathrm{C}\right)$ & $c(\mathrm{~g} / \mathrm{L})$ & $\mathrm{pH}$ & $k_{1}\left(\mathrm{~h}^{-1}\right)$ & $E_{\mathrm{a}}$ & \\
\hline \multirow{3}{*}{$\mathrm{GA}$} & 25 & 2.15 & 4 & 0.30 & & HCN-Lennart Larsson \\
\cline { 2 - 6 } & 15 & & 5 & 0.42 & & \\
& 20 & & & 0.09 & & Seawater -J.Epstein..$^{[5]}$ \\
\hline
\end{tabular}




\begin{tabular}{|c|c|c|c|c|c|c|}
\hline GB & 0.2 & & & 2.63 & & $\begin{array}{c}\text { Seawater - } \\
\text { M.M.Demek. }{ }^{[6]}\end{array}$ \\
\hline GD & & & $\begin{array}{c}3 \\
7 \\
10\end{array}$ & $\begin{array}{c}0.03 \\
8.66 \times 10^{-3} \\
1.73\end{array}$ & & T.V Healy. ${ }^{[7]}$ \\
\hline \multirow[t]{2}{*}{ VX } & 25 & $\begin{array}{l}2.03 \\
2.51 \\
4.89 \\
5.25 \\
\end{array}$ & & $\begin{array}{l}2.36 \times 10^{-2} \\
2.30 \times 10^{-2} \\
2.55 \times 10^{-2} \\
2.43 \times 10^{-2} \\
\end{array}$ & & Zhao Guohui [3] ${ }^{[3]}$ \\
\hline & 25 & & & $4.00 \times 10^{-3}$ & & $\begin{array}{c}\text { Seawater - } \\
\text { M.M.Demek. }\end{array}$ \\
\hline \multirow[t]{2}{*}{ HD } & $\begin{array}{l}20 \\
10 \\
15 \\
20 \\
25 \\
30 \\
\end{array}$ & & & $\begin{array}{c}5.16 \\
1.61 \\
3.0 \\
5.57 \\
11.12 \\
16.7 \\
\end{array}$ & 85.5 & Xue Jishen $^{[8]}$ \\
\hline & $\begin{array}{c}5 \\
15 \\
25\end{array}$ & & & $\begin{array}{l}0.24 \\
0.85 \\
2.76\end{array}$ & 84.2 & Seawater -J.Epstein. ${ }^{[9]}$ \\
\hline $\mathrm{CG}$ & 20 & $\begin{array}{l}8.68 \times 10^{-4} \\
2.44 \times 10^{-3} \\
8.26 \times 10^{-4}\end{array}$ & & $\begin{array}{l}0.18 \\
0.18 \\
0.21\end{array}$ & & Xue Jishen ${ }^{[8]}$ \\
\hline $\mathrm{BZ}$ & 25 & $3.50 \times 10^{-2}$ & & $3.35 \times 10^{-3}$ & & Xue Jishen ${ }^{[8]}$ \\
\hline
\end{tabular}

Table 2. Rate constants and activation energies of heterogeneous hydrolysis of various poisons

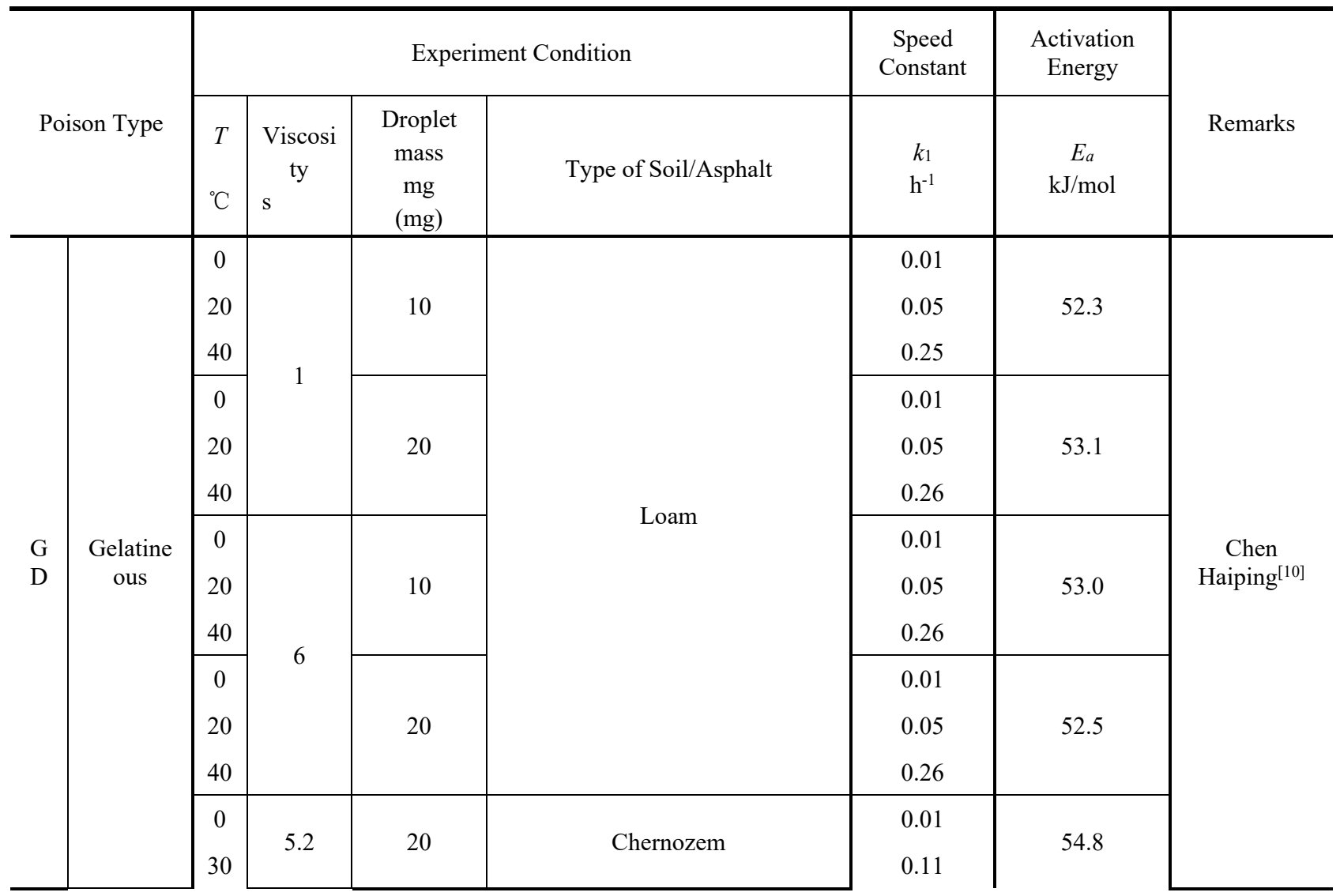




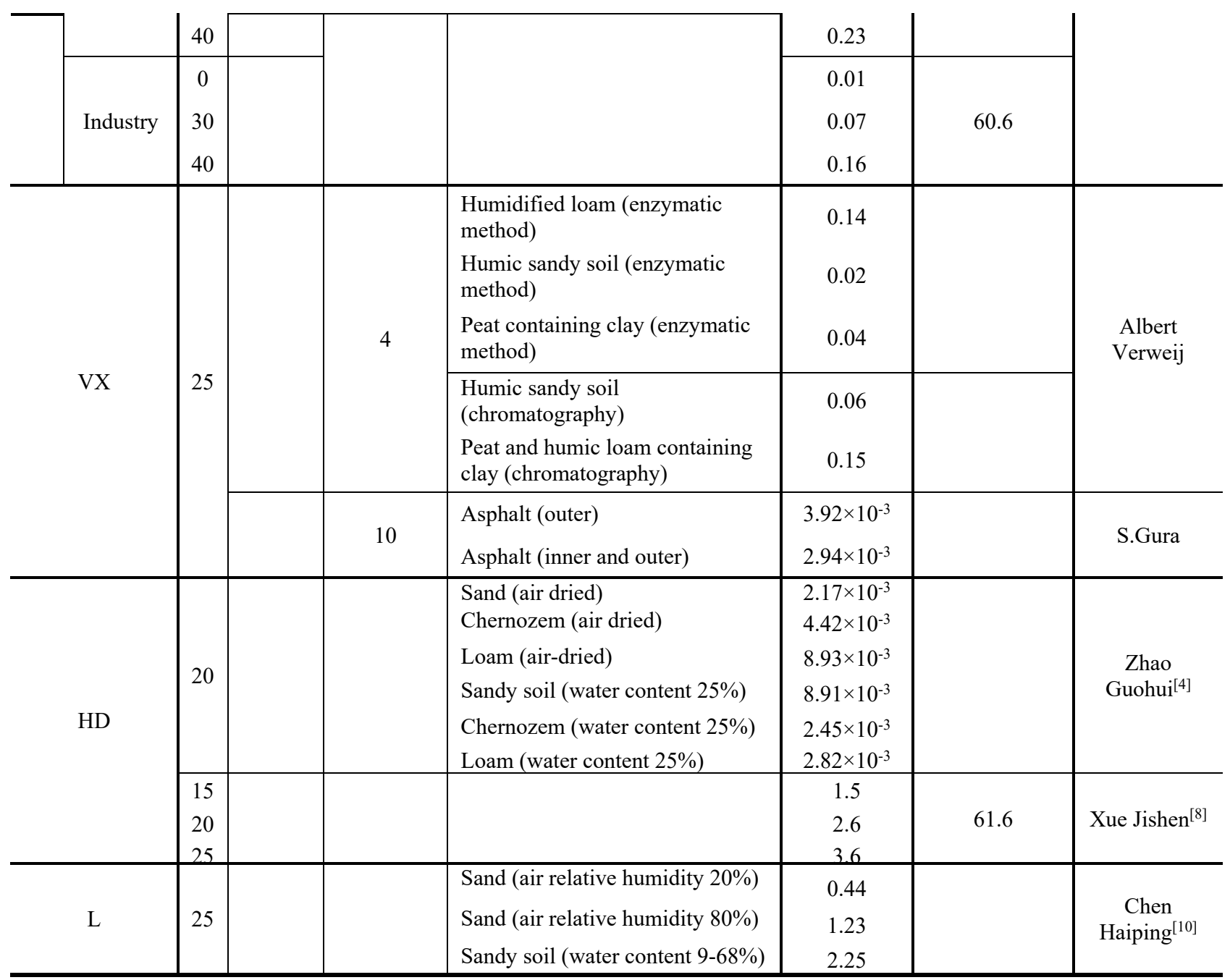

\subsection{Heterogeneous hydrolysis of poison}

The degradation of toxic agents in soil mainly occurs in heterogeneous hydrolysis of toxic agents, and the hydrolysis process is closely related to soil temperature, soil water content, soil structural composition and dispersion degree of venom drops. The hydrolysis reaction rate of colloidal GD accelerates with the increase of temperature, which accords with arrhenius formula relationship, and the activation energy is about $50 \mathrm{~kJ} / \mathrm{mol}$ However, when the mass and viscosity of GD droplets change, the hydrolysis reaction rate basically changes; The hydrolysis rate of industrial GD is lower than that of colloidal GD because colloidal GD has stronger hygroscopicity. In loam and chernozem, the hydrolysis reaction of colloidal GD has the same apparent activation energy. The hydrolysis rate constant of HD in sandy soil, chernozem and loam is in the order of $10^{-3}$, while the activation energy of heterogeneous hydrolysis in water is about $61.6 \mathrm{~kJ} / \mathrm{mol}$. The hydrolysate of Lewis gas is oxidized vinyl chloride arsine, which is easy to hydrolyze in pure water, air and soil. At the same time, it can be found that the hydrolysis is faster in soil with high water content.

\section{Conclusions}

For the eight different types of poisons discussed in this paper, the hydrolysis rate constants of homogeneous and heterogeneous phase can be calculated by first-order kinetic reaction equation, and the relationship between hydrolysis rate constants and temperature can be obtained according to arrhenius formula. Poison concentration, system $\mathrm{pH}$, environmental temperature and soil structural composition will all affect the hydrolysis rate of poison. A full understanding of the hydrolysis behavior of poison is conducive to the development and use of disinfectant.

\section{References}

1. George O B. Handbook of Chemical and Biological Warfare Agent Decontamination.2012

2. Zhu B C. Chemical Reaction Engineering [M]. Beijing: Chemical Industry Press. 1991

3. Cheng Z X. Nuclear, biochemical decontamination agent and its application [M]. Beijing: Tsinghua University Press. 2015

4. J. Epstein, D. H. Rosenblatt. Summary Report on a Data Base for Predicting Consequences of Chemical 
Disposal Operations, EASP1200-12,1973.

5. M. M. Demek, G.T. Davis. Behavior of Chemical Agents in Seawater. Edgewood Arsenal, MD,1970.

6. T.V Healy. Kinetics of the Hydrolysis Pinacolyl Methane Fluorophonate (GD). Chemical Defence Research Establishment, Porton Down, UK, 1948.

7. J. Epstein, D. H. Rosenblatt. Summary Report on a Data Base for Predicting Consequences of Chemical Disposal Operations, Edgewood Arsenal, MD, 1970.

8. Chen H P, Wang X Y. Effect and Destruction of Chemical Weapons [M]. Beijing: Weapons Industry Press, 2002. 